\title{
A RANDOMIZED, DOUBLE-BLIND CLINICAL TRIAL COMPARING THE 22 VERSUS 26 GAUGE NEEDLE IN THE PRODUCTION OF THE POST-LUMBAR PUNCTURE SYNDROME IN NORMAL INDIVIDUALS
}

\author{
WALLACE W. TOURTELLOTTE, M.D., Ph.D.1 \\ WILLIAM G. HENDERSON, Ph.D.2 \\ R. PAUL TUCKER, M.D. \\ OLOF GILLAND, M.D., Ph.D. ${ }^{3}$ \\ JONATHAN E. WALKER, M.D.4 \\ EMRE KOKMAN, M.D.
}

\begin{abstract}
From the Department of Neurology, University of Michigan, Ann Arbor, Michigan 48104 USA. Sponsored by Michigan Chapter of the National Multiple Sclerosis Society and International Center of the National Multiple Sclerosis Society for the Collection, Storage and Distribution of Control and Multiple Sclerosis Tissue.
\end{abstract} ${ }^{1}$ Chief, Neurology Service, VA Hospital (Wadsworth), and Professor and Vice-Chairman, Department of Neurology,
University of California, Los Angeles.

\author{
${ }^{2}$ Assistant Professor of Biostatistics, University of lowa, School of Dentistry, lowa City, lowa. \\ ${ }^{3}$ Associate Professor of Neurology, Box 138, Neurology Klinik, 41475 Göteborg, Sweden. \\ ${ }^{4}$ Assistant Professor of Neurology, University of Colorado Medical School, Denver, Colorado.
}

THE MULTITUDE of factors involved in the etiology of the post-lumbar puncture headache (PPH) were surveyed in a previous monograph. ${ }^{1}$ That study indicated several factors to be of prime importance, including needle size, sex, and age. The present study was designed to evaluate. more precisely the effect of needle size on the production of the PPH. Sex differences in the incidence of PPH are also examined. A review of previous studies in this field is given in the monograph cited and will not be repeated here. Some further references may be found in a study by Gilland ${ }^{2}$ dealing with the probable usefulness of a waist belt in combating the PPH.

\section{MATERIALS AND METHODS}

\section{Experimental Groups and Punctures}

One hundred consecutive healthy volunteers who were rated normal on physical and neurological examinations were included in the study. Sixty were male and 40 were female. Their average age was 23.2 years, with a range of 20-41. Members of each successive pair of incoming volunteers were randomly assigned to either the 22 gauge (O.D. $0.71 \mathrm{~mm}$.) needle group or the 26 gauge (O.D. $0.46 \mathrm{~mm}$.) needle group, one member to each group.

Punctures were performed with a technique previously described, ${ }^{1}$ adding the refinements of the guiding cannula technique for the 26 gauge needle, also previously discussed. 3 In short, punctures were performed with the subjects in the left lateral recumbent position, without local anesthesia or sedation, subjects remained recumbent for 1 hour post-puncture.

Consistently noted were the number of sticks required to put the needle in the proper position, the number of times the needle was spun around for patency of the needle tip, the presence of blood in the fluid at any time, and the duration of the tap in minutes. Only one jugular compression (Queckenstedt test) was performed in each individual. The amount of fluid withdrawn by means of a $5 \mathrm{ml}$. syringe from each subject was $20 \mathrm{ml}$. With the aid of a stopwatch, the withdrawal rate was standardized to $1 \mathrm{ml}$. per minute. The needle was never left indwelling for more than 25 minutes, nor for less than 21 minutes.

As appears in Table I, no significant differences $(p<0.05)$ in the technical aspects of the study were noted between the two experimental groups. There were fairly large, though insignificant, differences in sex $(66 \%$ males in the 26 gauge needle group versus $54 \%$ males in 


\section{TABLE I}

Test of Equality of the Two Needle Groups in Some Important Factors (Other Than Needle Size) Potentially Affecting

Outcome of Lumbar Puncture

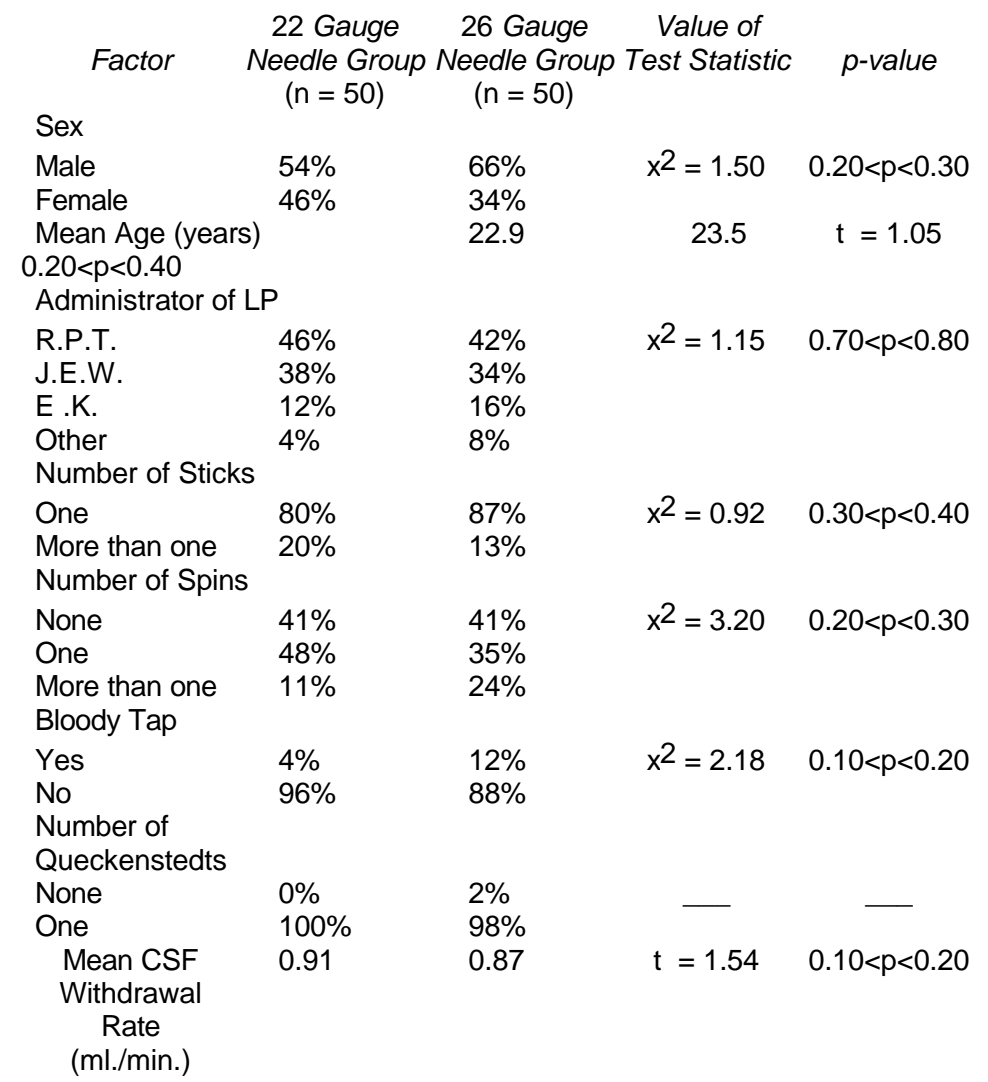

the 22 gauge group) and in the percentage of bloody taps (12\% versus $4 \%$, respectively).

The subjects were blinded with respect to size of needle used. They were all interviewed by the same neurologist (W.W.T.), who was also blinded as to needle size. The volunteers were followed for one week unless significant complaints were observed, in which case the follow-up was continued until complaints had ended.

\section{Systems of Grading Post-Lumbar Punuture Complaints}

An Overall Evaluation. To gain an overall perspective of the difference between the 22 and 26 gauge needle groups in the production of all symptoms considered together, the subjects were placed into one of the following three mutually exclusive and exhaustive categories:

\section{No complaints:}

The week following the lumbar puncture (LP) was completely uneventful for the subject, i.e., the subject had no complaints whatsoever regarding aftereffects of the LP.

\section{Some "minor" complaints only:}

"Minor" complaints were defined as any complaints from aftereffects of the LP short of a postural headache. These non-incapacitating complaints included such symptoms as headaches for only a short period immediately after the LP, minimal to mild nonpostural headaches, unusual tiredness on the day of the LP, slight numbness, and insomnia.

\section{"Major" complaints:}

"Major" complaints included mild to severe postural headaches which were often incapacitating and accompanied by other complaints such as backaches, unusual tiredness, anorexia, nausea and vomiting, and weight loss. 
Headaches. For a more detailed analysis of headaches, the severity of each headache was graded on a 0-4 scale for each day that it persisted, and the grades for each day were summed to obtain a total score for each subject. The $0-4$ severity scale was defined as follows:

$0=$ Normal, no headache

$1=$ Minimal, non-postural, non-incapacitating headache

$2=$ Mild postural headache, but not significantly interfering with normal daily activity

$3=$ Moderate postural headache causing the subject to lie down during the day and restricting normal activity for part of the day

4 = Severe postural headache causing the subject to be bedridden for the entire day

Based upon the total severity scores, each postural headache was further classified as mild (total severity score from 1 to 9), moderate (total severity score from 10 to 15), or severe (total severity score of 16 and above).

Backaches. The severity of each backache was graded according to the following scheme:

Normal $=$ No backache

Minimal $=$ Backache on day of LP only or at most one day after LP

Mild = Slight non-incapacitating backache lasting more than one day but no more than 2 days

Moderate $=$ Backache lasting more than 2 days and made worse by bending, but not incapacitating

Severe $=$ Incapacitating backache lasting more than one day

Other complaints. All other post-lumbar puncture complaints were graded individually as present or absent.

Influence of Needle Size

\section{RESULTS}

Table II summarizes the comparisons between needle groups for the variety of symptoms associated with lumbar puncture.

Overall evaluation. The presence of any post-lumbar puncture complaints as related to needle size appears in line 1 of Table II, while the percent of all complaints which were considered to be "major" as related to needle size appears in line 2 . Seventy-five percent of the volunteers reported some type of com-

\section{TABLE II}

Comparison of the 22 Gauge Needle (O.D. $0.71 \mathrm{~mm}$.) and the 26 Gauge Needle (O.D. $0.46 \mathrm{~mm}$.) With Respect to Various Post-Lumbar Puncture Symptoms (Percent with Symptom)

\begin{tabular}{|c|c|c|c|c|}
\hline & 22 Gauge & 26 Gauge & & \\
\hline Symptom & $\begin{array}{l}\text { Veedle Group } \\
(\mathrm{n}=50)\end{array}$ & $\begin{array}{l}\text { Needle Group } \\
\quad(n=50)\end{array}$ & $x^{2}$-value & $p$-value \\
\hline $\begin{array}{l}\text { Presence of any complaints } \\
\text { Percent of all complaints which }\end{array}$ & $78 \%$ & $72 \%$ & 0.48 & $0.40<p<0.50$ \\
\hline were considered to be "major" & $46 \%$ & $17 \%$ & 7.48 & $0.005<\mathrm{p}<0.01$ \\
\hline $\begin{array}{l}\text { Presence of postural headache } \\
\text { Percent of postural headaches }\end{array}$ & $36 \%$ & $12 \%$ & 7.89 & $p=0.005$ \\
\hline $\begin{array}{l}\text { which were severe } \\
\text { Percent of Postural headaches }\end{array}$ & $44 \%$ & $0 \%$ & 4.00 & $0.025<\mathrm{p}<0.05$ \\
\hline accompanied by nausea & $72 \%$ & $33 \%$ & 2.90 & $0.05<p<0.10$ \\
\hline $\begin{array}{l}\text { Presence of backaches } \\
\text { Percent of backaches which were }\end{array}$ & $72 \%$ & $56 \%$ & 2.78 & $0.05<p<0.10$ \\
\hline $\begin{array}{l}\text { moderate or severe } \\
\text { Presence of miscellaneous }\end{array}$ & $14 \%$ & $7 \%$ & 0.44 & $0.50<p<0.60$ \\
\hline mplaints & $34 \%$ & $10 \%$ & 8.39 & $0.0005<\mathrm{p}<0.005$ \\
\hline
\end{tabular}


plaint following LP, 78\% in the 22 gauge needle group and $72 \%$ in the 26 gauge needle group. In this overall respect there was no significant difference $(0.40<p<0.50)$ between the two groups. However, when severity of the complaints is considered, $46 \%$ of the complaints were "major" in the 22 gauge group while only $17 \%$ were "major" in the 26 gauge group $(0.005<\mathrm{p}<0.01)$. Thus, whenever an LP is done, some complaints may be expected from a majority of the subjects, no matter what needle size is used. The severity of the symptoms is significantly reduced, however, with the use of the 26 gauge needle.

Headaches. The incidence of postural headaches as related to needle size appears in line 3 of Table II. Use of the 22 gauge needle resulted in $36 \%$ of the subjects developing a postural headache as compared to $12 \%$ with the 26 gauge needle. This difference was highly significant $(p=0.005)$. The incidences of non-postural headaches were equal $(14 \%)$ in the two groups.

Postural headaches were found to be not only three times as frequent in the 22 gauge needle group, but also more severe. A plot of the postural headaches by severity appears in Figure 1. As may be seen, all 6 subjects in the 26 gauge group who developed postural headaches suffered a mild to moderate variety only.

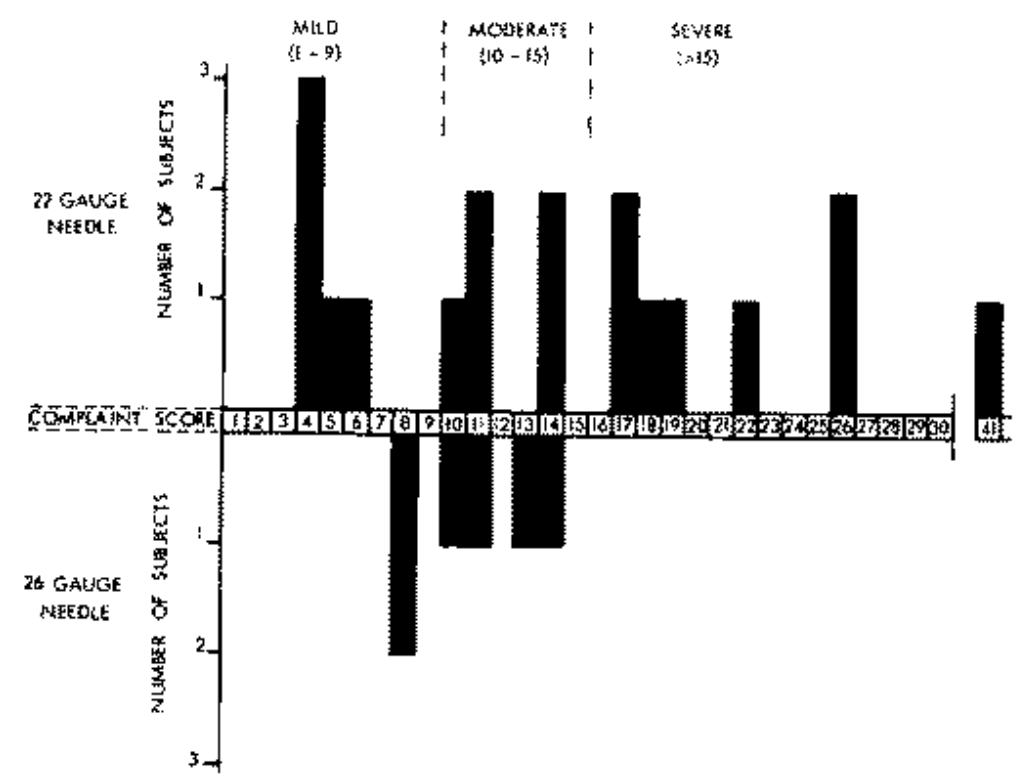

FIG. 1- Frequency and Severity of Postural Headaches Produced by 2:2 and 26 Gauge Needies. See "lext for Complaint score and the definition of mild, moderate, and severe postural headashes.

In the 22 gauge group, in addition to the 10 who suffered the mild to moderate variety, there were 8 who suffered from severe postural headaches. This difference is statistically significant, $0.025<\mathrm{p}<0.05$ (line 4 of Table II).

Furthermore, postural headaches in the 22 gauge needle group tended to have more nausea associated with them than did postural headaches in the 26 gauge needle group, $72 \%$ vs. $33 \%$, respectively (line 5 of Table II). This result was close to statistical significance $(0.05<\mathrm{p}<0.10)$.

All non-postural headaches in both experimental groups, with the exception of one, had total severity scores from 1 to 3 , indicating that they were minimal short-lasting headaches.

Backaches. The 22 gauge needle group had more backaches than did the 22 gauge needle group, $72 \%$ versus $56 \%$ (line 6 of Table II). This difference was close to being statistically significant $(0.05<p<0.10)$. There appeared to be little difference in severity between the backaches in the 22 gauge needle group and those in the 26 gauge needle group (line 7 of Table II).

Miscellaneous complaints. A significantly larger number of subjects in the 22 gauge group complained of miscellaneous after effects, $34 \%$ versus 10\% (line 8 of Table II). These miscellaneous complaints included nausea with or without vomiting, numbness, unusual tiredness, anorexia, weight loss, and neckache.

\section{Sex Differences in Response to Lumbar Puncture}

It appeared worthwhile to compare male versus female response to lumbar puncture. Table III summarizes the comparisons between sexes for the variety of symptoms associated with lumbar puncture. There were two statistically significant differences $(p<0.05)$ between the sexes, occuring for the percent of all 


\section{TABLE III}

Comparison of Males and Females With Respect to Various Post-Lumbar Puncture Symptoms (Percent with Symptom)

\section{Symptom}

\section{Presence of any complaints}

$$
\begin{array}{cc}
\text { Males } & \text { Females } \\
(\mathrm{n}=60) & (\mathrm{n}=40) \\
77 \% & 72 \%
\end{array}
$$

Percent of all complaints which were

considered to be "major"

$x^{2}$-value

p-value

Presence of postural headache $\quad 17 \%$

Percent of postural headaches which

were severe

$17 \%$

$55 \%$

0.22

$0.60<p<0.70$

Percent of postural headaches

accompanied by nausea

$25 \%$

$40 \%$

11.67

$\mathrm{p}<0.0005$

$0.0005<p<0.005$

Presence of backaches

$75 \%$

$38 \%$

0.38

$0.50<p<0.60$

Percent of backaches which were

moderate or severe $\quad 10 \%$

Presence of miscellaneous complaints
$17 \%$
$30 \%$
2.49

$0.30<\mathrm{p}<0.40$

$0.70<p<0.80$

$\begin{array}{lll}56 \% & 0.80 & 0.30<p<0.40 \\ 62 \% & 0.07 & 0.70<p<0.80 \\ 12 \% & 0.05 & 0.80<p<0.90 \\ 30 \% & 2.49 & 0.10<p<0.20\end{array}$

complaints which were considered to be "major" and the incidence of postural headaches. Fifty-five percent of all females registering complaints were considered to have "major" complaints, while only $17 \%$ of all males registering complaints had "major" complaints. Also, $40 \%$ of the females reported postural headaches, while only $13 \%$ of the males reported them.

Furthermore, the incidence for postural headaches for males and females with a 22 or 26 gauge needle was registered as follows:

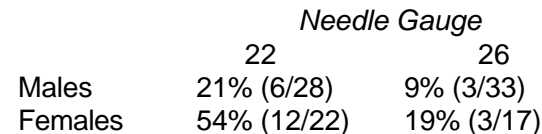

Accordingly, a 26 gauge needle significantly reduced the incidence for PPH in both males and females.

\section{DISCUSSION}

The use of the 26 gauge needle will thus reduce, on the average, the number who suffer a postural headache, from one out of every three subjects punctured to one out of every nine subjects puncturad. Furthermore, the subject who suffers a PPH after a 26 gauge needle puncture most likely will have a mild to moderate postural headache, whereas every second postural headache produced by a 22 gauge needle will be severe.

There are certain drawbacks with the 26 gauge needle technique. It does require minimal additional training beyond that necessary for larger needles. Furthermore, it is sometimes difficult to manipulate the needle tip into a position where it does not get intermittently obstructed by nerve root filaments. The rate of fluid withdrawal is slower, and a syringe is needed.

From the diagnostic point of view, only static pressure readings can be performed when using a 26 gauge needle in combination with an open end manometer. With an isometric transducer, however, even Queckenstedt responses can be as adequately recorded as with larger size needles. ${ }^{3}$ Injection of contrast material such as Pantopaque through a 26 gauge needle at $35^{\circ}$ limits the rate to about $1 \mathrm{ml}$. per minute, and the removal rate to about $1 \mathrm{ml}$. per 5 minutes. This could make the 26 gauge needle impractical for myelography studies if it is deemed necessary to remove all the Pantopaque ${ }^{(r)}$ from the CSF space.

Comparison of the 22 gauge needle with the 26 gauge is a severe test of the 
hypothesis that PPH is do to the leakage of spinal fluid through the inflicted rent. If a larger needle, e.g., 18 gauge, had been used our results would probably have been even more striking. ${ }^{1}$ The recent studies demonstrating persistent leaks with radioactive tracers could also be mentioned to support this theory about PPH. 4,5 Furthermore, we suggested sometime ago that if the leak could be plugged with fibrin PPH should be eliminated. ${ }^{1}$ The strategy we suggested was to withdraw the needle joint just outside of the subarachnoid membrane, or epidural and inject fibrinogen. Recently, this type of experiment has been performed; 6 and it was considered an effective treatment; the source of fibrinogen was the patient's own blood. Hence, it is proved almost beyond reasonable doubt now that PPH is due to leakage of spinal fluid at the lumbar puncture site faster than it is formed, $0.35 \mathrm{ml}$ per minute; 7 this reduces the circulating spinal fluid volume. This spinal fluid volume reduction permits the brain to shift downward enough in the upright position to stretch the pain innervated basal meninges which signals a headache.

\section{SUMMARY}

In the present study 100 volunteers who were punctured to obtain normal cerebrospinal fluid were randomly assigned to either a 22 or 26 gauge needle group. Their average age was 23.2 years with a range of 20-41. Sixty were male and 40 were female. A double-blind follow-up of post-puncture symptoms was carried out, with documentation of numerous factors considered to be relevant.

It was found that, while there was a $75 \%$ incidence of some type of complaint in both needle groups, "major" complaints were only one third as frequent in the 26 gauge group. The incidences of postural headaches in the 22 and 26 gauge needle groups were $36 \%$ and $12 \%$, respectively. Furthermore, none of the postural headaches produced by the 26 gauge needle was severe, whereas $44 \%$ of them in the 22 gauge needle group were severe. Nausea was associated with $72 \%$ of the postural headaches in the 22 gauge group, and only $33 \%$ in the 26 gauge group. Backaches were also more frequent in the 22 gauge group (72\% versus $56 \%$ ), the difference being close to statistical significance. Females were found to suffer postural headaches significantly more frequently than males (40\% versus $13 \%)$.

The advantages and disadvantages of fine gauge needles in various clinical applications are also discussed.

\section{REFERENCES}

1. Tourtellotte, W.W., Haerer, A.F., Hiller, G.L., and Somers, J.E.: Post-Lumbar Puncture Headaches. Springfield: Charles C. Thomas, 1964.

2. Gilland, O.: How to Take the Headache Out of Spinal Taps, Headache, 8:154, 1969.

3. Gilland, O.: CSF Dynamic Diagnosis of Spinal Block: Theory and Practice of Electromanometrics. Stockholm: Almqvist \& Wiksell, 1966.

4. Lieberman, L.M., Tourtellotte, W.W., and Newkirk, T.A.: Prolonged post-lumbar puncture cerebrospinal fluid leakage from lumbar subarachnoid space demonstrated by radioisotope myelography. Neurology, 21: 925-929, 1971.

5. Gass, H., Goldstein, A.S., Ruskin, R., Leopold, N.: Chronic postmyelogram headache. Arch. Neurol., 25: 168-170, 1971.

6. DiGiovanni, A., and Dunbar, B.S.: Epidural injection of autologous blood for post-lumbar puncture. Anesth. Analges (Cleve.), 49: 268-271, 1970.

7. Cutler, R.W.P., Page, L., Galicich, J., and Watters, G.V.: Formation and absorption of cerebrospinal fluid in man. Brain, 91:707-720, 1968.

Address reprint requests to:

Dr. Wallace W. Tourtellotte

Neurology Service $(691 / 180)$

VA Wadsworth Hospital Center

Los Angeles, CA 90073 